\title{
In vitro susceptibilities of clinical isolates of Escherichia coli and Klebsiella species to CSE1034 and other $\beta$-lactams
}

\author{
Manu Chaudhary, Shailesh Kumar and Anurag Payasi \\ The Journal of Antibiotics (2013) 66, 495-497; doi:10.1038/ja.2013.29; published online 24 April 2013
}

Keywords: CSE1034; Escherichia coli; Klebsiella Spp.; susceptibility

Infections are becoming difficult to treat with commonly used antibiotics when caused by extended spectrum $\beta$-lactamase (ESBL)and metallo- $\beta$-lactamase (MBL)-producing organisms. ${ }^{1}$ In recent years, the antibiotic resistance against ESBL-producing organisms has increased at an alarming rate. ${ }^{2}$ To overcome the antibiotic resistance caused by ESBL producers, carbapenems were introduced in clinical settings. However, carbapenem resistance among the members of the Enterobacteriaceae family has been reported globally. ${ }^{3}$

In view of the increasing antibiotic-resistance problems because of ESBL and MBL, a combination of ceftriaxone with sulbactam and EDTA, altogether termed as CSE1034, was developed, which has been found to be effective against ESBL-producing organisms. ${ }^{4,5}$ However, its efficacy against isolates harboring MBL and ESBL $+\mathrm{MBL}$ is yet to be explored. Therefore, in vitro susceptibilities of MBL- and ESBL + MBL-positive Escherichia coli and Klebsiella spp. isolates to CSE1034 and other $\beta$-lactams were investigated.

A total of 151 isolates of phase-III clinical trial including E. coli (96, 63.57\%), Klebsiella spp. (Klebsiella pneumoniae (34, 22.51\%) and Klebsiella oxytoca $(21,13.90 \%)$ ) were obtained from 278 patients suffering from skin and skin structure infections (SSSIs), bone and joint infections (BJIs), lower respiratory infections (LRTIs), urinary tract infections (UTIs), bacterial septicemia (BS) and chronic suppurative otitis media (CSOM) enrolled in 18 centers across India. Each isolate's identity was confirmed as described earlier. ${ }^{6}$ All isolates were screened for ESBL and MBL by the Clinical and Laboratory Standards Institute methods $(\mathrm{CLSI})^{7}$ and were then subjected to characterization for the types of ESBL and MBL genes. ${ }^{8-10}$ The susceptibility testing was performed according to the CLSI method. ${ }^{7}$

The antibiotics included for in vitro study were as follows: CSE1034 $(1.5 \mathrm{~g})$, ceftriaxone $(1 \mathrm{~g})$, piperacillin plus tazobactam $(4.5 \mathrm{~g})$, cefoperazone plus sulbactam $(2 \mathrm{~g})$ and imipenem plus cilastatin $(0.5 \mathrm{~g})$.

Out of the 96 E. coli received, 75 were from UTIs, 10 from BS, 7 from LRTIs, 3 from BJIs and 1 from CSOMs. Out of the
34 K. pneumoniae, 9 were from CSOMs, 8 from SSSIs, 7 from LRTIs, 4 from UTIs, 3 from BS and 3 from BJIs; of the $21 \mathrm{~K}$. oxytoca, 7 were from CSOMs, 6 from UTIs, 4 from SSSIs, 3 from LRTIs and 1 from BS. The screening results confirmed that 50 isolates were ESBL producers, 15 were MBL producers and 86 had coproduced both ESBL and MBL. In E. coli, TEM-1, TEM-2 and TEM-50 were observed in 27, 17 and 7 isolates, respectively, whereas SHV-1 and SHV-10 were found in 58 and 10 isolates, respectively. NDM-1, VIM-1 and IMP-1 were found in 28, 17 and 16 isolates, respectively. Similarly, in Klebsiella spp., TEM-1, TEM-2 and TEM-4 were observed in 16, 18 and 2 isolates, respectively, whereas SHV-1 and SHV-2 were found in 35 and 2 isolates, respectively. NDM-1, VIM-1 and IMP-1 were found in 7, 28 and 26 isolates, respectively.

In vitro antibacterial susceptibility data are presented in Table 1. CSE1034 was the most active antibacterial agent with the majority of ESBL-producing E. coli displaying $93.02 \%$ susceptibility, whereas MBL- and ESBL + MBL-producing isolates exhibiting $100 \%$ susceptibility. Imipenem plus cilastatin appeared to be the second most active agent with $67.44 \%$ susceptibility, followed by piperacillin plus tazobactam (58.14\%), cefoperazone plus sulbactam (55.81\%) and ceftriaxone (51.16\%). However, E. coli harboring ESBL + MBL exhibited $86.36 \%, 95.45 \%, 90.90 \%$ and $100 \%$ resistance to imipenem plus cilastatin, piperacillin plus tazobactam, cefoperazone plus sulbactam and ceftriaxone, respectively. Klebsiella spp. (K. oxytoca and K. pneumoniae) appeared to be highly susceptible to CSE1034 (100\% to each of ESBL- and MBL-producing isolates, and 93-96\% to ESBL + MBL-producing isolates). ESBL-producing Klebsiella spp. were equally susceptible to imipenem plus cilastatin and piperacillin plus tazobactam (66-75\%), and susceptibilities of cefoperazone plus sulbactam and ceftriaxone varied from 33 to $50 \%$ and 25 to $33 \%$, respectively. However, ESBL + MBL-producing Klebsiella spp. showed 100\% resistance to ceftriaxone followed by $96-100 \%$ to each of the piperacillin 
Table 1 In vitro activity of CSE1034 and other comparator antibiotics

Susceptibility of clinical isolates

\begin{tabular}{|c|c|c|c|c|c|c|c|}
\hline \multirow[b]{2}{*}{ Organism (number of isolates) } & \multirow[b]{2}{*}{ antibiotics } & \multicolumn{2}{|c|}{$E S B L$} & \multicolumn{2}{|c|}{$M B L$} & \multicolumn{2}{|c|}{$E S B L+M B L$} \\
\hline & & $\begin{array}{c}\% \text { of isolate } \\
\text { susceptibility }\end{array}$ & $\begin{array}{c}\% \text { of isolate } \\
\text { resistant }\end{array}$ & $\begin{array}{c}\% \text { of isolate } \\
\text { susceptibility }\end{array}$ & $\begin{array}{c}\% \text { of isolate } \\
\text { resistant }\end{array}$ & $\begin{array}{l}\% \text { of isolate } \\
\text { susceptibility }\end{array}$ & $\begin{array}{c}\% \text { of isolate } \\
\text { resistant }\end{array}$ \\
\hline \multirow{5}{*}{ Escherichia coli (96) } & Imipenem + cilastatin & 67.44 & 32.55 & - & 100 & 13.64 & 86.36 \\
\hline & Piperacillin + tazobactam & 58.14 & 41.86 & - & 100 & 4.55 & 95.45 \\
\hline & Cefoperazone + sulbactam & 55.81 & 44.19 & - & 100 & 9.09 & 90.90 \\
\hline & CSE1034 & 93.02 & 6.98 & 100 & - & 100 & \\
\hline & Ceftriaxone & 51.16 & 48.84 & - & 100 & - & 100 \\
\hline \multirow[t]{5}{*}{ Klebsiella oxytoca (21) } & Imipenem + cilastatin & 66.66 & 33.33 & - & 100 & 12.5 & 87.5 \\
\hline & Piperacillin + tazobactam & 66.66 & 33.33 & - & 100 & - & 100 \\
\hline & Cefoperazone + sulbactam & 33.33 & 66.66 & - & 100 & - & 100 \\
\hline & CSE1034 & 100 & & 100 & - & 93.75 & 6.25 \\
\hline & Ceftriaxone & 33.33 & 66.66 & - & 100 & - & 100 \\
\hline \multirow[t]{5}{*}{ Klebsiella pneumoniae (34) } & Imipenem + cilastatin & 75 & 25 & - & 100 & 15.38 & 84.61 \\
\hline & Piperacillin + tazobactam & 75 & 25 & - & 100 & 3.84 & 96.15 \\
\hline & Cefoperazone + sulbactam & 50 & 50 & - & 100 & 3.84 & 96.15 \\
\hline & CSE1034 & 100 & - & 100 & - & 96.15 & 3.84 \\
\hline & Ceftriaxone & 25 & 75 & - & 100 & - & 100 \\
\hline
\end{tabular}

Abbreviations: $\mathrm{ESBL}$, extended spectrum $\beta$-lactamase; $\mathrm{MBL}$, metallo- $\beta$-lactamase.

Among the 96 E. coli, ESBL-, MBL- and ESBL+MBL-producing E. coli were 43,9 and 44 , respectively. Similarly, in $K$. oxytoca, ESBL-, MBL- and ESBL+ MBL-producing $K$. oxytoca were 3,2 and 16 , respectively, and for K. pneumoniae, ESBL-, MBL- and ESBL + MBL-producing K. pneumoniae were 4, 4 and 26, respectively.

Table 2 MIC distributions for isolates obtained from various clinical specimens

Number of isolates and MIC $\left(\mu g \mathrm{ml}^{-1}\right)$ :

\begin{tabular}{|c|c|c|c|c|c|c|c|c|c|c|}
\hline Organisms (number of isolates) & Antibiotics & Characteristic of isolates & 2 & 4 & 8 & 16 & 32 & 64 & 128 & $>128$ \\
\hline \multirow[t]{13}{*}{ Escherichia coli (96) } & \multirow[t]{3}{*}{ Imipenem + cilastatin } & MBL & & & & & & 2 & 5 & 2 \\
\hline & & ESBL & & & 6 & 9 & 14 & 5 & 9 & \\
\hline & & $\mathrm{ESBL}+\mathrm{MBL}$ & & & 1 & 2 & 3 & 10 & 21 & 7 \\
\hline & \multirow{3}{*}{ Piperacillin + tazobactam } & MBL & & & & & & 1 & 3 & 5 \\
\hline & & ESBL & & & 2 & 11 & 12 & 6 & 4 & 8 \\
\hline & & $\mathrm{ESBL}+\mathrm{MBL}$ & & & & 1 & 1 & 12 & 13 & 17 \\
\hline & \multirow{2}{*}{ Cefoperazone + sulbactam } & MBL & & & & & & & 4 & 5 \\
\hline & & ESBL & & & 1 & 11 & 12 & 3 & 6 & 10 \\
\hline & \multirow{3}{*}{ CSE1034 } & $\mathrm{ESBL}+\mathrm{MBL}$ & & & & 1 & 3 & 8 & 20 & 12 \\
\hline & & $\begin{array}{l}\mathrm{MBL} \\
\mathrm{FSBL}\end{array}$ & & 4 & 2 & 3 & 4 & $?$ & & \\
\hline & & $\mathrm{ESBL}+\mathrm{MBL}$ & & 2 & 16 & 4 & 22 & 3 & & \\
\hline & \multirow[t]{2}{*}{ Ceftriaxone } & $\mathrm{MBL}$ & & & & & & & 1 & 8 \\
\hline & & $\begin{array}{l}\text { ESBL } \\
\text { ESBL }+M B L\end{array}$ & & & & 6 & 16 & 8 & $\begin{array}{l}5 \\
8\end{array}$ & 8 \\
\hline \multirow[t]{13}{*}{ Klebsiella oxytoca (21) } & \multirow[t]{3}{*}{ Imipenem + cilastatin } & MBL & & & & & & 1 & $\begin{array}{l}8 \\
1\end{array}$ & \\
\hline & & ESBL & & & & 2 & 1 & 1 & & \\
\hline & & $\mathrm{ESBL}+\mathrm{MBL}$ & & & & 1 & 1 & 6 & 4 & 4 \\
\hline & \multirow[t]{3}{*}{ Piperacillin + tazobactam } & $\mathrm{MBL}$ & & & & & & & 1 & 1 \\
\hline & & ESBL & & & & & 2 & & 1 & \\
\hline & & $E S B L+M B L$ & & & & & & 2 & 3 & 11 \\
\hline & \multirow[t]{2}{*}{ Cefoperazone + sulbactam } & $\begin{array}{l}M B L \\
E S B L\end{array}$ & & & & & & & & 2 \\
\hline & & $\begin{array}{l}\mathrm{ESBL} \\
\mathrm{ESBL}+\mathrm{MBL}\end{array}$ & & & & & 1 & & $\begin{array}{l}1 \\
2\end{array}$ & $\begin{array}{r}1 \\
14\end{array}$ \\
\hline & \multirow[t]{3}{*}{ CSE1034 } & $\mathrm{MBL}$ & & & & 1 & 1 & & & \\
\hline & & ESBL & & & 1 & 2 & & & & \\
\hline & & $\mathrm{ESBL}+\mathrm{MBL}$ & & & 1 & 6 & 8 & 1 & & \\
\hline & \multirow[t]{2}{*}{ Ceftriaxone } & MBL & & & & & & & & 2 \\
\hline & & $\begin{array}{l}\mathrm{ESBL} \\
\mathrm{ESBL}+\mathrm{MBL}\end{array}$ & & & & 1 & 1 & & $\begin{array}{l}1 \\
8\end{array}$ & 8 \\
\hline \multirow[t]{13}{*}{ Klebsiella pneumoniae (34) } & \multirow[t]{3}{*}{ Imipenem + cilastatin } & MBL & & & & & & 3 & $\begin{array}{l}0 \\
1\end{array}$ & \\
\hline & & ESBL & & & & 2 & 1 & 1 & & \\
\hline & & $\mathrm{ESBL}+\mathrm{MBL}$ & & & & 3 & 1 & 10 & 4 & 8 \\
\hline & \multirow[t]{3}{*}{ Piperacillin + tazobactam } & MBL & & & & & & 1 & 2 & 1 \\
\hline & & ESBL & & & & & 3 & 1 & & \\
\hline & & 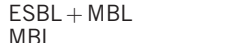 & & & & & 1 & 6 & 10 & 9 \\
\hline & \multirow{2}{*}{ Cefoperazone + sulbactam } & $\begin{array}{l}\text { MBL } \\
\text { ESBL }\end{array}$ & & & & 1 & 1 & & 2 & 2 \\
\hline & & $\mathrm{ESBL}+\mathrm{MBL}$ & & & & & 1 & 4 & 8 & 13 \\
\hline & \multirow{3}{*}{ CSE1034 } & MBL & & & & 2 & 2 & & & \\
\hline & & ESBL & & & 1 & 2 & 1 & & & \\
\hline & & $\mathrm{ESBL}+\mathrm{MBL}$ & & & 3 & 12 & 10 & 1 & & \\
\hline & \multirow{2}{*}{ Ceftriaxone } & $\begin{array}{l}\text { MBL } \\
\text { ESBL }\end{array}$ & & & & & 1 & & & \\
\hline & & $\mathrm{ESBL}+\mathrm{MBL}$ & & & & & 1 & 2 & 4 & 2 \\
\hline
\end{tabular}

Abbreviations: ESBL, extended spectrum $\beta$-lactamase; MBL, metallo- $\beta$-lactamase. 
plus tazobactam and cefoperazone plus sulbactam, and $84-87 \%$ to imipenem plus cilastatin. Interestingly, the most important observation of this study was that all MBL-producing isolates (E. coli and Klebsiella spp.) were almost $100 \%$ resistant to all the comparator antibiotics.

With regard to MIC distributions (Table 2), CSE1034 MICs fell within $4-32 \mu \mathrm{g} \mathrm{ml}^{-1}$ against $97 \%$ of E. coli and $96 \%$ of Klebsiella spp. The MIC distributions of ceftriaxone, imipenem plus cilastatin, piperacillin plus tazobactam and cefoperazone plus sulbactam for E. coli isolates varied between 8 and $>128$. Imipenem plus cilastatin and ceftriaxone MICs varied between 16 and $>128$, and piperacillin plus tazobactam and cefoperazone plus sulbactam MICs were 32 to $>128$ for Klebsiella spp.

CSE1034 showed intermediate-to-resistant response to TEM-50positive isolates. However, it appeared to be highly susceptible to NDM-1-, VIM-1- and IMP-1-positive isolates. Imipenem plus cilastatin, piperacillin plus tazobactam, cefoperazone plus sulbactam and ceftriaxone that were resistant to NDM-1-, VIM-1-, IMP-1- and TEM-50-positive isolates, however, were found to be susceptible to those isolates positive with TEM-1, TEM-2 and SHV-1. The enhanced susceptibility of CSE1034 against E. coli and Klebsiella spp. is likely to be associated with synergistic activity of ceftriaxone plus sulbactam plus EDTA. ${ }^{11,12}$ The CSE1034 enhanced the susceptibility by altering the outer-membrane permeability, which in turn increased penetration of drug inside the bacterial cells. Furthermore, EDTA chelates the divalent ions required for the activity of MBL, thus enhancing the susceptibility of CSE1034 toward MBL-producing organisms. Our previous studies also demonstrated the enhanced in vitro efficacy of CSE1034..$^{5,6,11,13}$ Studies in animal models also demonstrated promising in vivo efficacy of CSE1034. ${ }^{14,15}$

The results obtained in the present study confirmed the broad-spectrum activity of CSE1034 against the MBL- and ESBL + MBL-producing organisms. Hence, CSE1034 can be considered as a drug of choice for the treatment of infections caused by these organisms.

\section{ACKNOWLEDGEMENTS}

This work was supported by Venus Pharma GmbH, AM Bahnhof 1-3, D-59368 Werne, Germany. We thank to all centers that provided isolates.

1 Paterson, D. L. \& Bonomo, R. A. Extended-spectrum $\beta$-lactamases: a clinical update. Clin. Microbiol. Rev. 18, 657-686 (2005)

2 Meyer, E., Schwab, F., Schroeren-Boersch, B. \& Gastmeier, P. Dramatic increase of third-generation cephalosporin-resistant $E$. coli in German intensive care units: secular trends in antibiotic drug use and bacterial resistance, 2001 to 2008. Crit. Care 14, R113 (2010).

$3 \mathrm{Hu}, \mathrm{F}$. et al. Emergence of carbapenem-resistant clinical Enterobacteriaceae isolates from a teaching hospital in Shanghai, China. J. Med. Microbiol. 61, 132-136 (2012).

4 Payasi, A., Kumar, S. \& Chaudhary, M. A comparative study of sulbactomax versus ceftriaxone and beta-lactamase inhibitor and their effect on mutant prevention in ESBL producing organisms. Int. J. Drug Dev. Res. 3, 366-371 (2011).

5 Chaudhary, M. \& Payasi, A. Comparative efficacy of antibiotics in biofilms eradication formed by ESBL and non ESBL producing micro-organisms. Int. J. Drug Dev. Res. 4, 138-147 (2012).

6 Bergey, D. H., Buchanan, R. E. \& Gibbons, N. E. Bergey's Manual of Determinative Bacteriology (Williams \& Wilkins Co., Baltimore, MD, USA, 1975).

7 Clinical and Laboratory Standards Institute (CLSI). (Performance Standards for Antimicrobial Susceptibility Testing, Approved Standards CLSI M100-S20, Wayne, PA: USA 2010).

8 Hussain, $M$. et al. Prevalence of class $A$ and AmpC beta-lactamases in clinical Escherichia coli isolates from Pakistan Institute of Medical Science, Islamabad, Pakistan. Jpn. J. Infect. Dis. 64, 249-252 (2011).

9 Poirela, L., Walsh, T. R., Cuvilliera, V. \& Nordmanna, P. Multiplex PCR for detection of acquired carbapenemase genes. Diag. Microbiol. Infect. Dis. 70, 119-123 (2011).

10 Sharma, J., Sharma, M. \& Ray, P. Detection of TEM \& SHV genes in Escherichia coli \& Klebsiella pneumoniae isolates in a tertiary care hospital from India. Indian J. Med. Res. 132, 332-336 (2010).

11 Chaudhary, M. \& Payasi, A. Role of EDTA and CSE1034 in curli formation and biofilm eradication of Klebsiella pneumoniae: a comparison with other drugs. J. Antibiotics 65, 631-633 (2012).

12 Chaudhary, M., Sudaroli, M., Kumar, S. \& Krishnai, R. Catering ESBL resistance challenge through strategic combination of ceftriaxone, sulbactam and ethylenediaminetetraacetic acid. Int. J. Drug Dev. Res. 4, 72-81 (2012).

13 Chaudhary, M., Kumar, S. \& Payasi, A. A novel approach to combat acquired multiple resistance in Escherichia coli by using EDTA as efflux pump inhibitor. J. Microb. Biotech. 4, 126-130 (2012).

14 Dwivedi, V. K., Kumar, P. \& Chaudhary, M. Comparative study of CSE1034 and ceftriaxone in pneumonia induced rat. Clin. Exp. Pharmacol. 2, 108 (2012).

15 Dwivedi, V. K., Bhatnagar, A. \& Chaudhary, M. Prevention of cadmium toxicity by ceftriaxone plus sulbactam with VRP1034 in rats. J. Drug Metab. Toxicol. 3, 5 (2012). 